\title{
Curcumin Is an In Vivo Inhibitor of Angiogenesis
}

\author{
Jack L. Arbiser, ${ }^{1,2}$ Nancy Klauber, ${ }^{2}$ Richard Rohan, ${ }^{2}$ \\ Robert van Leeuwen, ${ }^{1}$ Mou-Tuan Huang, ${ }^{3}$ Carolyn Fisher, ${ }^{3}$ \\ Evelyn Flynn, ${ }^{2}$ and $H$. Randolph Byers ${ }^{4}$ \\ ${ }^{\mathrm{l}}$ Department of Dermatology, Harvard Medical School, Boston, \\ Massachusetts, U.S.A. \\ ${ }^{2}$ Department of Surgical Research, Childrens Hospital, Harvard \\ Medical School, Boston, Massachusetts, U.S.A. \\ ${ }^{3}$ Department of Chemical Biology, College of Pharmacy, Rutgers-The \\ State University of New Jersey, Piscataway, New Jersey, U.S.A. \\ ${ }^{4}$ Department of Dermatology, Boston University School of Medicine, \\ Boston, Massachusetts, U.S.A. \\ Communicated by P. Talalay. Accepted April 9, 1998.
}

\begin{abstract}
Background: Curcumin is a small-molecular-weight compound that is isolated from the commonly used spice turmeric. In animal models, curcumin and its derivatives have been shown to inhibit the progression of chemically induced colon and skin cancers. The genetic changes in carcinogenesis in these organs involve different genes, but curcumin is effective in preventing carcinogenesis in both organs. A possible explanation for this finding is that curcumin may inhibit angiogenesis.

Materials and Methods: Curcumin was tested for its ability to inhibit the proliferation of primary endothelial cells in the presence and absence of basic fibroblast growth factor (bFGF), as well as its ability to inhibit proliferation of an immortalized endothelial cell line. Curcumin and its derivatives were subsequently tested for their ability to inhibit bFGF-induced corneal neovas-
\end{abstract}

cularization in the mouse cornea. Finally, curcumin was tested for its ability to inhibit phorbol ester-stimulated vascular endothelial growth factor (VEGF) mRNA production.

Results: Curcumin effectively inhibited endothelial cell proliferation in a dose-dependent manner. Curcumin and its derivatives demonstrated significant inhibition of bFGF-mediated corneal neovascularization in the mouse. Curcumin had no effect on phorbol ester-stimulated VEGF production.

Conclusions: These results indicate that curcumin has direct antiangiogenic activity in vitro and in vivo. The activity of curcumin in inhibiting carcinogenesis in diverse organs such as the skin and colon may be mediated in part through angiogenesis inhibition.

\section{Introduction}

Curcumin is a carotenoid pigment found in the rhizome of Curcuma longa, source of turmeric

Address correspondence and reprint requests to: Dr. Jack L. Arbiser, Department of Dermatology, Emory University School of Medicine, WMB 5001, Atlanta, GA 30022. Phone: (404) 727-5872; Fax: (404) 727-5878; E-mail: jlarbiser@bics.bwh.harvard.edu
$(1,2)$. Turmeric is a major component of the diet of the Indian subcontinent. Administration of curcumin to mice treated with skin and colon carcinogens has been shown to result in a decreased incidence and size of tumors compared with control mice (3-7). The exact mechanism of curcumin's chemopreventive activities is not fully understood. Curcumin has been demon- 
strated to inhibit several signal transduction pathways, including those involving protein kinase $\mathrm{C}$, the transcription factor NF-kB, phospholipase A2 bioactivity, arachidonic acid metabolism, antioxidant activity, and epidermal growth factor (EGF) receptor autophosphorylation $(8-12)$. Precisely how inhibition of these pathways relates to curcumin's antitumor effect is uncertain.

Colon and skin cancers are major public health problems in Westernized nations. Hereditary colon cancers account for up to $20 \%$ of colon carcinoma in the United States. Several genes have been shown to contribute to colon carcinogenesis in human disease and transgenic mice (13-15). These syndromes are usually autosomal dominant, and they include familial adenomatous polyposis and nonpolyposis syndromes. In mice, phospholipase A2 expression has been demonstrated to be a co-factor in genetically susceptible mice (15). In addition, deletion of the cyclooxygenase 2 gene in colon carcinoma-prone Apc mice results in suppression of intestinal polyposis (16). Loss of $p 53$ and activation of ras oncogenes appear later in tumor progression $(17,18)$. Human skin cancers constitute the most common form of human neoplasia and are increasing in incidence, primarily as a result of sun exposure. In contrast to colon carcinoma, mutations of the $p 53$ gene are felt to arise early in ultraviolet-induced cutaneous carcinogenesis. Given that curcumin has protective effects against both colon and skin cancer, but the genes involved in tumor progression of skin and colon cancer differ, we hypothesized that the antitumor effects of curcumin may be due in part to angiogenesis inhibition.

Here we demonstrate that curcumin inhibits basic fibroblast growth factor (bFGF)-induced proliferation of endothelial cells in vitro and angiogenesis in vivo. We also tested the effect of curcumin analogs with known differential chemopreventive activities on in vivo angiogenesis. Our findings indicate that inhibition of angiogenesis may underlie in part the antitumor activity of curcumin in vivo.

\section{Materials and Methods}

\section{Endothelial Proliferation Assays}

Bovine capillary endothelial cells were isolated according to the method of Folkman et al. (19) and were plated at a concentration of 10,000 cells/well in gelatinized 24-well dishes. The pri- mary endothelial cells were cultured in Dulbecco's modified Eagle's medium (DMEM) supplemented with $10 \%$ bovine serum and grown at $37^{\circ} \mathrm{C}$ in $10 \% \mathrm{CO}_{2}$. Twenty-four hours after plating, cells were treated with curcumin in the presence or absence of bFGF. After $72 \mathrm{hr}$ of treatment, cells were counted using a Coulter counter. Cell counts for each condition were repeated in triplicate and in the presence or absence on $1 \mathrm{ng} / \mathrm{ml}$ bFGF. Similarly, MS 1 (ATCC CCRL 2279) endothelial cells, which are a SV40 large $\mathrm{T}$ antigen immortalized murine endothelial cell line (20), were also plated at a concentration of 10,000 cells/well in nongelatinized 24 -well dishes. MSl cells do not require endothelial mitogens for growth and were cultured in DMEM supplemented with $5 \%$ fetal calf serum (FCS). Cells were counted after a 72-hr exposure to curcumin with the same method used for the bovine capillary endothelial cells.

\section{Evaluation of bFGF-Induced Corneal Neovascularization by Curcumin and Curcumin Analogs}

Pellets were prepared according to a modification of the method of Kenyon et al. (21). An aqueous solution of $80 \mathrm{ng}$ of basic fibroblast growth factor (Scios Nova, Mountain View, CA) was evaporated to dryness under reduced pressure in the presence of $10 \mathrm{mg}$ of sucralfate (Bukh Meditec, Vaerlose, Denmark). Ten microliters of $12 \%$ hydron and $10 \mathrm{mg}$ of curcumin or curcumin analogs were then added, and the homogenous mixture was deposited onto a sterile $15 \times 15 \mathrm{~mm}$ 3-300/50 nylon mesh (Tetko, Lancaster, NY) and air dried. Once the mixture was dry, the mesh was manually dissociated to yield 225 pellets. Each pellet contained $80 \mathrm{ng}$ of bFGF and $44 \mu \mathrm{g}$ of curcumin or curcumin analog. In our prior experience (21), pellets containing Hydron in the absence of bFGF have not caused neovascularization, so pellets prepared in the absence of bFGF were not used in this study. The approximate pore size was $0.4 \times 0.4 \mathrm{~mm}$. Both sides of the mesh were covered with a thin layer of Hydron.

C57BL6 male mice (5-6 weeks old) were anesthetized with methoxyflurane prior to implantation of pellets and with $0.5 \%$ proparacaine. A central, intrastromal linear keratotomy was performed with a surgical blade, and a lamellar micropocket was prepared according to the method of Kenyon et al. (21). The pellet was advanced to the end of the pocket. Erythromycin 
ointment was placed on the operated eye to prevent infection. Eyes were examined by slit lamp on days 3-6 after implantation under general anesthesia. Corneal angiogenesis is assayed through two measurements. The first measurement, vessel length, is the length of the vessel from the corneal limbus as it grows toward the bFGF pellet. Clock hours is a measurement of neovascularized area of the cornea. The cornea is viewed as a circle that can be divided as a clock, with a maximum of $12 \mathrm{hr}$. Thus, a measurement of 3 clock hours implies that one-quarter of the cornea is vascularized. This system of measurement was established by Kenyon et al. (21).

\section{RNAse Protection for VEGF}

HaCaT keratinocytes (22) were grown in (DMEM) (JRH) supplemented with 5\% FCS (Hyclone, Logan, UT) in $25 \mathrm{~cm}^{2}$ flasks. One hour prior to stimulation with 12-O-tetradecanoylphorbol-13-acetate (TPA), cells were switched to serumless media supplemented with $10 \mu \mathrm{M}$ curcumin or an equal quantity of ethanol (final concentration $0.1 \%$ ). TPA was added to a final concentration of $5 \mathrm{ng} / \mathrm{ml}$ and incubated for $3 \mathrm{hr}$ at $37^{\circ} \mathrm{C}$. Cells were harvested and RNA extracted with guanidinium thiocyanate/phenol.

A plasmid containing the coding region of human vascular endothelial growth factor (VEGF) 121 was obtained from H. Weich (University of Freiburg, Germany), and used to generate $\mathrm{P}^{32}$-labeled antisense riboprobe as per manufacturers protocols (Ambion, Austin, TX). RNAse protection assays were performed according to the method of Hod (23). Protected fragments were separated on gels of $5 \%$ acrylamide, $8 \mathrm{M}$ urea, $1 \times$ Tris-borate buffer, and quantified with a phosphorimager (Molecular Dynamics, Sunnyvale, CA). An $18 \mathrm{~S}$ riboprobe was included in each sample to normalize for variations in loading and recovery of RNA.

\section{Phase II Enzyme Induction}

The ability of curcumin derivatives to induce phase II activities was measured by assaying quinone reductase $[\mathrm{NAD}(\mathrm{P}) \mathrm{H}:$ (quinone-acceptor) oxidoreductase, EC 1.6.99.2] in murine Hepaclc7 cells. Serial dilutions of curcumin, curcumin derivatives, and tetraphenylcyclopentadienone (TPCPD) were added, and the concentration of compound required to double the specific activity (CD) was calculated according to the method of Prochaska et al. (24).
Statistics

Significant differences between two groups were determined using an unpaired, two-tailed Student's $t$ test. Results are expressed as the mean \pm standard error of the mean.

\section{Results}

Inhibitory Effect of Curcumin on Endothelial Proliferation in the Presence or Absence of $b F G F$

Endothelial cells are stimulated to proliferate in the presence of $1 \mathrm{ng} / \mathrm{ml}$ bFGF. Curcumin was added in concentrations ranging from 0.5 to 10 $\mu \mathrm{M}$ to primary endothelial cells. A steep decrease in cell number was seen at $10 \mu \mathrm{M}$. No evidence of cytotoxicity was observed, and the number of cells at the end of treatment was not significantly less than the number of cells originally plated. This decrease was observed in both the presence or absence of bFGF (Fig. 1). In addition, curcumin was able to inhibit the growth of endothelial cells immortalized by SV40 large $\mathrm{T}$ antigen, with a similar dose response as seen with primary endothelial cells.

Curcumin Inhibits bFGF-Induced Neovascularization in the Mouse Cornea

The ability of curcumin to inhibit bFGF-induced corneal neovascularization in vivo was studied. Pellets were prepared containing $80 \mathrm{ng}$ of bFGF and curcumin, or a control aromatic ketone, tetraphenylcyclopentadienone (TPCPD). TPCPD was added to rule out the possibility that the inhibition of neovascularization due to curcumin was not secondary to dilution. There was no difference in neovascularization in mice containing bFGF pellets in the presence or absence of TPCPD (data not shown). Neovascularization was assessed by slit lamp at 5 days after implantation, and the corneas were photographed. Both the vessel length and clock hours were significantly reduced in the presence of curcumin (Fig. 2).

\section{Curcumin Analogs Inhibit bFGF-Induced}

Neovascularization in the Mouse Cornea

Curcumin analogs were assayed for their ability to inhibit bFGF-induced corneal neovascularization as described above. All analogs showed inhibitory activity, with demethoxycurcumin showing the greatest activity on both clock hours and vessel length, tetrahydrocurcumin having 

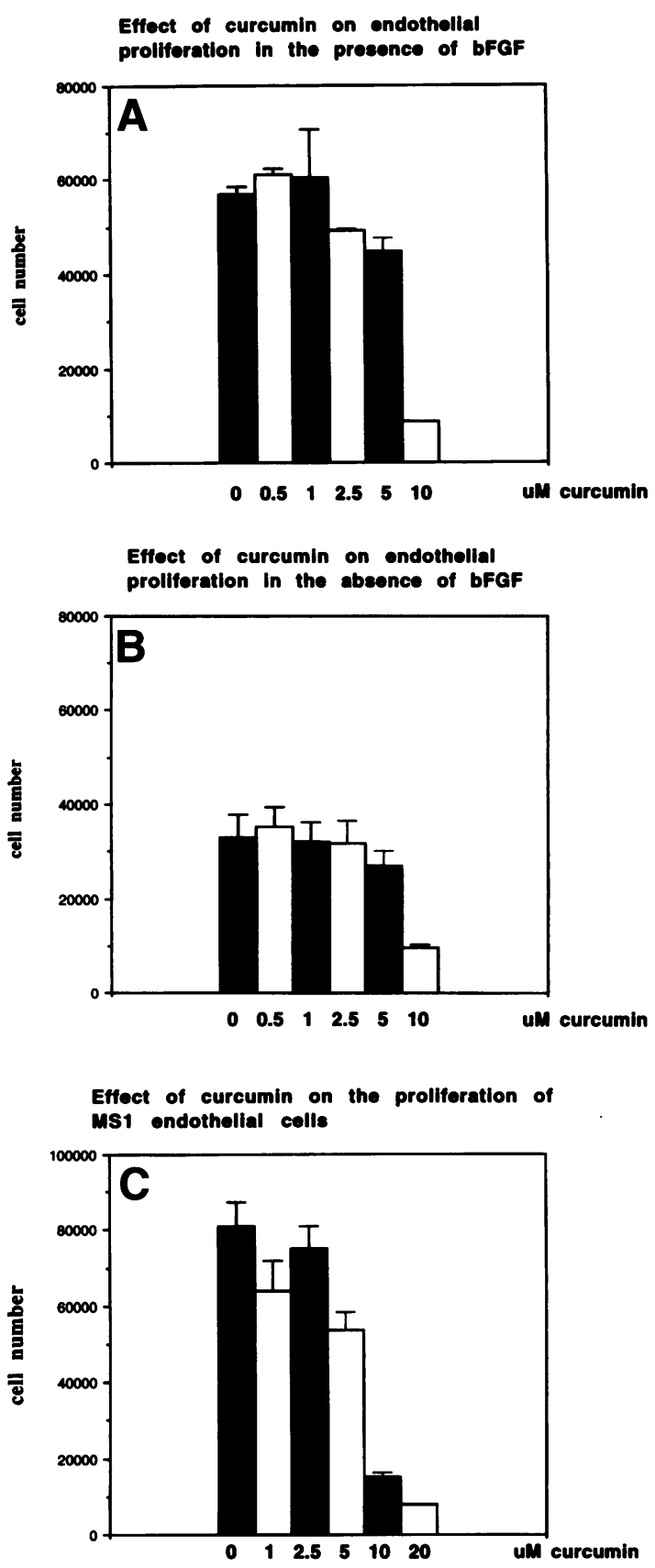

Fig. 1. Effect of curcumin on the proliferation of capillary endothelial cells. Cells were grown in the presence or absence of $\mathrm{bFGF}$ and doses of curcumin ranging from 0 to $20 \mu \mathrm{M}$ curcumin. The $y$ axis denotes the cell number after $72 \mathrm{hr}$. (A) Effect of curcumin on primary capillary endothelial cells stimulated with $1 \mathrm{ng} / \mathrm{ml}$ of bFGF. (B) Effect of curcumin on the proliferation of unstimulated primary capillary endothelial cells. (C) Effect of curcumin on immortalized endothelial cells. The error bars represent standard error of the mean. the least effect on clock hours, and bisdemethoxycurcumin having the least effect on vessel length (Fig. 3). All of the curcumin derivates showed significant inhibition of bFGF-mediated neovascularization compared with control pellets.

\section{Effect of Curcumin on VEGF Production by Transformed Keratinocytes}

HaCaT cells are derived from spontaneously transformed human keratinocytes (22). In order to determine whether curcumin could inhibit production of angiogenesis factors by relevant tumor cells as well as directly inhibit endothelial function; we treated $\mathrm{HaCaT}$ cells with tetradecanoylphorbol ester (TPA) in the presence or absence of curcumin and assayed expression of VEGF mRNA. TPA caused a 2.5 -fold increase in VEGF mRNA, which was not inhibited by curcumin (Fig. 4). Thus the primary antiangiogenic effect of curcumin is directly on endothelium, rather than inhibition of production of VEGF, an important angiogenic factor.

Effect of Curcumin Derivatives on Induction of Phase II Enzyme Induction

Several plant-derived compounds with anticancer and chemopreventative activities also show the ability to induce phase II detoxifying enzymes, including quinone reductase. We wanted to determine whether the antiangiogenic activities of curcumin derivatives correlated with the ability to induce quinone reductase activity. The $\mathrm{CD}$ (concentration to double the specific activity) value for curcumin was $7.3 \mu \mathrm{M}, 9.0 \mu \mathrm{M}$ for demethoxycurcumin, and $11.0 \mu \mathrm{M}$ for bisdemethoxycurcumin. These $C D$ values are approximately equal, but they differ significantly from that of tetrahydrocurcumin. Tetrahydrocurcumin, the curcumin derivative with the least antitumor activity, caused a 1.6-fold induction of quinone reductase activity at $25 \mu \mathrm{M}$. However, TPCPD, which is an unsaturated aromatic ketone with no anti-angiogenic activity, had a $C D$ value of $4.8 \mu \mathrm{M}$. Thus, antiangiogenic activity does not correlate with phase II activity.

\section{Discussion}

Curcumin is a nontoxic, small-molecular-weight compound with established chemopreventive activity in areas of direct contact, such as the skin 

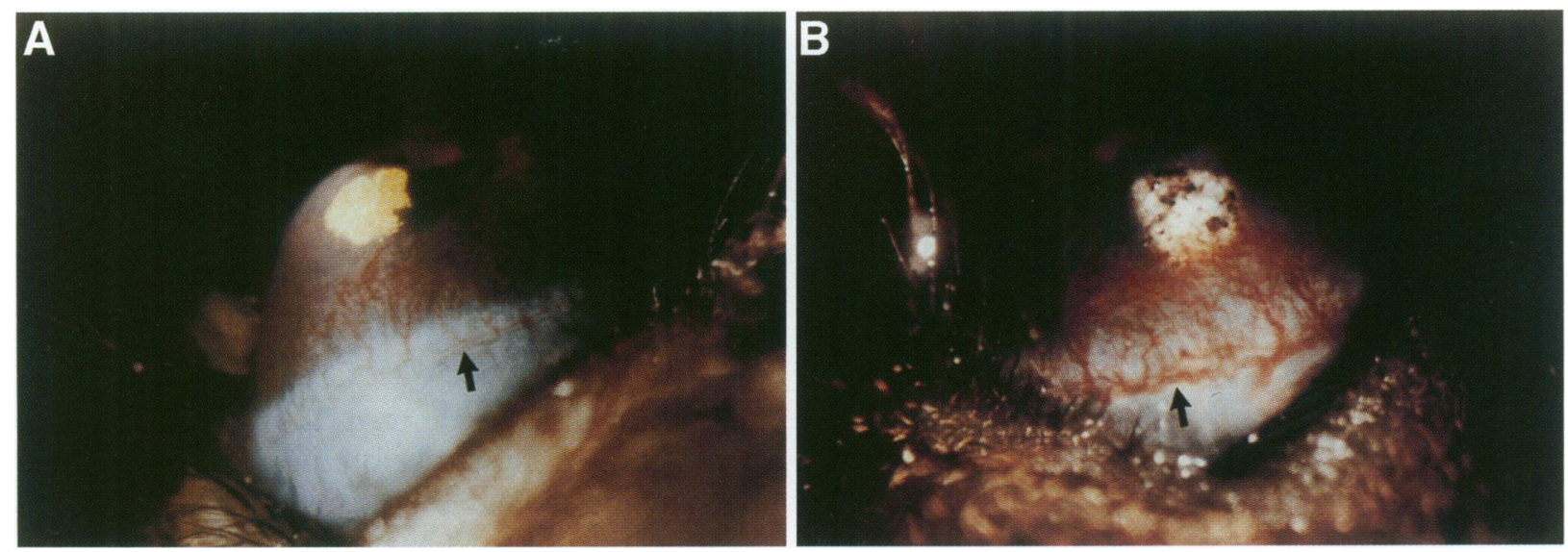

\section{C}

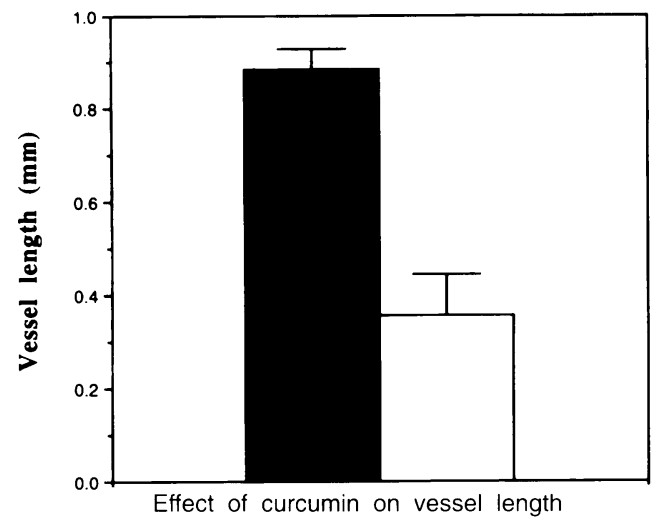

Fig. 2. Effect of curcumin on corneal neovascularization. (A, B) The photograph on the left shows a cornea containing bFGF and curcumin, while the cornea on the right contains TPCPD, a control substance, and an equal quantity (80 $\mathrm{ng}$ ) of bFGF. The arrows point to a corneal feeder vessel, which is enlarged in the absence of curcumin and is

and gastrointestinal tract (3-7). The reasons for its efficacy as a chemopreventive agent are not fully understood. Curcumin has been shown to possess several activities that may affect tumorigenesis in vivo. First, curcumin has been shown to inhibit tumor initiation by the carcinogens benzo(a)pyrene and 7,12,-dimethylbenzanthracene (DMBA), as well as tumor promotion induced by phorbol esters $(6,7,12)$. Curcumin has also been shown to inhibit phorbol ester-induced ornithine decarboxylase, a marker of cellular proliferation and tumorigenesis, in mouse skin. In addition, curcumin has an inhibitory effect on expression of c-fos and c-jun, oncogenes that form the transcription factor AP-1 $(8,10)$. These pathways also influence tumor cell proliferation in vivo, and curcumin may have a dual effect on inhibiting both tumor growth in vivo
D

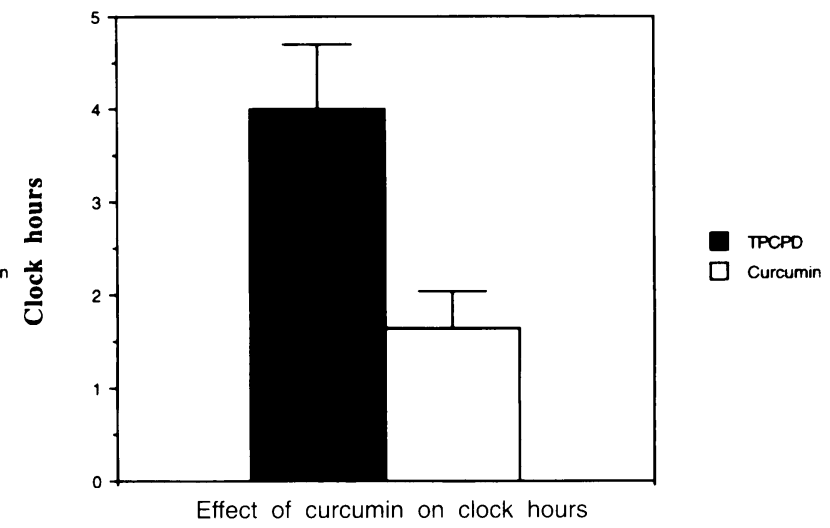

attenuated in the presence of curcumin. (C) The bar graph shows the effect of curcumin and TPCPD on vessel length. $p<0.05$. (D) The bar graph shows the effect of curcumin and TPCPD on clock hours, a measure of area. The error bars represent standard error of the mean.

through inhibiting tumor promotion, as well as inhibiting angiogenesis in tumors that have already undergone the angiogenic switch.

Basic fibroblast growth factor (bFGF) is a potent angiogenic factor. This factor has been shown to be a potent stimulus for both endothelial proliferation and migration. The activity of bFGF on endothelial cells may be due in part though stimulation of protein kinase $C(25)$. The corneal neovascularization assay, which measures vessel length and density in response to a bFGF pellet placed in the normally avascular cornea, has proven useful in the characterization of multiple angiogenesis inhibitors (21). Administration of curcumin or its analogs within the pellet resulted in potent inhibition of bFGF-induced corneal neovascularization. This inhibition was not due to dilution of bFGF, 


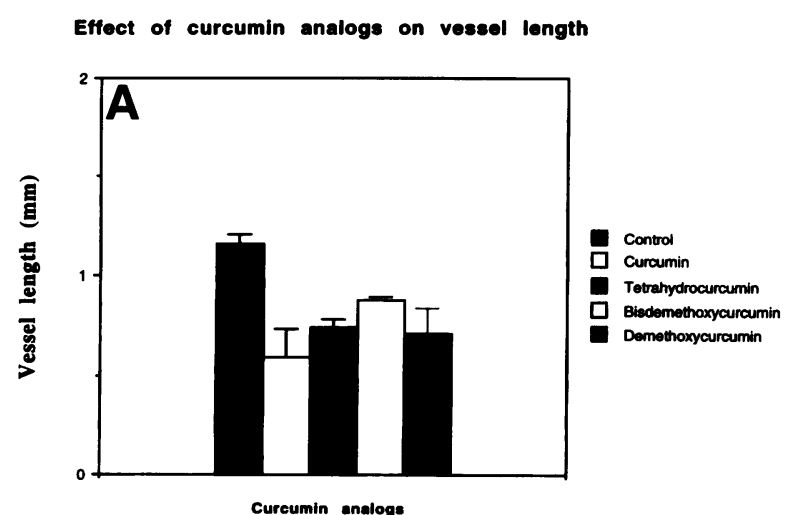

Effect of curcumin analogs on clock hours

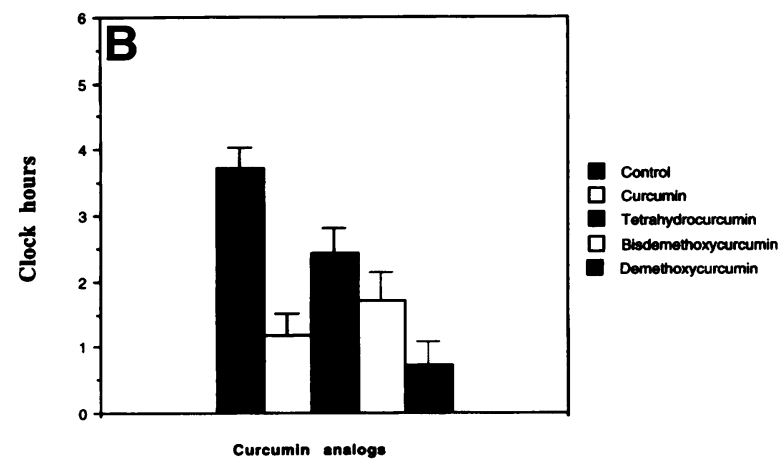

Fig. 3. Effect of curcumin analogs on corneal neovascularization. (A) Effect of curcumin analogs on vessel length. All curcumin derivatives show a significant difference in vessel length from controls at $p<0.05$. (B) Effect of curcumin analogs on clock hours. All curcumin derivatives show a significant difference in area from controls at $p<0.05$.

as administration of a structurally related inactive compound, tetraphenylcyclopentadienone (TPCPD), has no effect on bFGF-induced corneal neovascularization. Intraperitoneal administration of curcumin at doses up to $300 \mathrm{mg} / \mathrm{kg}$ did not inhibit corneal neovascularization (data not shown); this may be due to the well-known rapid metabolism of curcumin $(26,27)$. Higher doses of curcumin caused weight loss in mice.

Curcumin had a strong antiproliferative effect on endothelial cells, with a steep curve occurring between 5 and $10 \mu \mathrm{M}$. This was true both in the presence or absence of bFGF, and this inhibition could not be overcome by the immortalizing ability of SV40 large T antigen.

Food-grade curcumin consists of $77 \%$ curcumin, $17 \%$ demethoxycurcumin, and $3 \%$ bisdemethoxycurcumin. In a previous study, Huang et al. found that these three compounds were able to inhibit phorbol ester-stimulated induc-

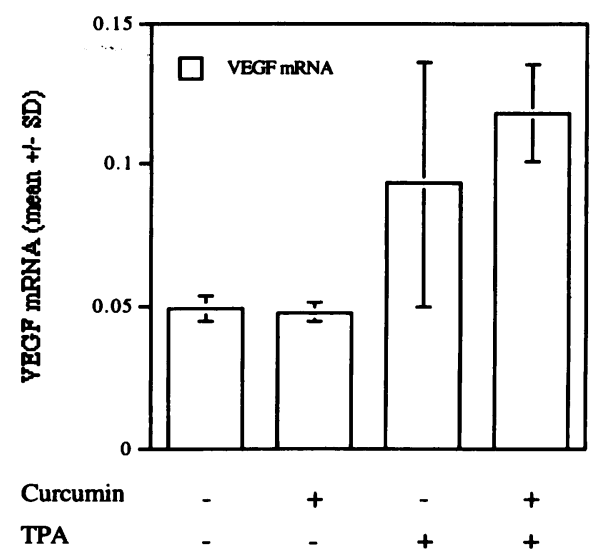

Fig. 4. Effect of curcumin on VEGF mRNA production in HaCat cells. The intensity of bands from VEGF RNAse protection were quantified by densitometry and normalized for loading by quantification of 18S RNA. The error bars represent standard error of the mean.

tion of ornithine decarboxylase and promotion of mouse skin initiated with 7,12-dimethylbenzanthracene (DMBA) (6). These derivatives also inhibited phorbol ester-mediated transformation of JB6 cells (8). The saturated derivative tetrahydrocurcumin was less active than the unsaturated derivatives in these assays. These curcumin analogs were placed into corneal pellets and assayed for angiogenesis inhibition. Pure curcumin, demethoxycurcumin, tetrahydrocurcumin, and bisdemethoxycurcumin were all active in inhibiting bFGF-induced corneal neovascularization, but to varying degrees. Curcumin, demethoxycurcumin, and bisdemethoxycurcumin are much more effective chemopreventive agents than tetrahydrocurcumin in vivo (6), although all of the derivatives have antiangiogenic activity. This may be due to other activities of curcumin, such as the ability to induce phase II detoxifying enzymes, which may inhibit further tumor promotion. All of the unsaturated curcumin derivatives have approximately equal potencies in induction of phase II enzymes, whereas the fully saturated tetrahydrocurcumin has little ability to induce phase II enzymes.

Angiogenesis inhibitors may be divided into two classes. The first class, or direct angiogenesis inhibitors, refer to those agents which are relatively specific for endothelial cells and have little effect on tumor cells (28). Examples of these include soluble VEGF receptor antagonists and angiostatin $(29,30)$. Indirect inhibitors may not have direct effects on endothelial cells but may 
down-regulate the production of an angiogenesis stimulator, such as VEGF $(20,31)$. VEGF has been shown to be up-regulated during chemically induced skin carcinogenesis; this is likely due to activation of oncogenes, such as $\mathrm{H}$-ras (20, $32,33)$. Examples of indirect inhibitors of angiogenesis include inhibitors of ras-mediated signal transduction, such as farnesyltransferase inhibitors (33). The antagonism of bFGF-mediated corneal neovascularization by curcumin and its derivatives suggests that curcumin is a direct angiogenesis inhibitor. The lack of inhibition of TPA-mediated VEGF production further supports the role of curcumin as a direct angiogenesis inhibitor.

Chemopreventive agents are a diverse group of compounds with multiple activities. These include inhibition of proliferation, enhancement of DNA repair, and induction of detoxifying enzymes, such as quinone reductase, for the removal of mutagenic xenobiotics (34). Fotsis et al. have found that the chemopreventive agent genistein can inhibit the proliferation of endothelial cells in vitro (35). We show that curcumin, another chemopreventive agent, is capable of inhibiting bFGF-mediated angiogenesis in vivo. The precise mechanism of how chemopreventive agents actually prevent neoplasia is not fully understood. Inhibition of angiogenesis may underlie in part the beneficial activity of chemopreventive agents.

\section{Acknowledgments}

J. L. A. was supported by NIH grant RO3AR44947 and grants from the Society for Pediatric Dermatology, the Dermatology Foundation, and the Thomas B. Fitzpatrick Research Award from the KAO Corporation. We acknowledge Albena Dinkova-Kostova for her assistance with the quinone reductase assays.

\section{References}

1. Ammon HP, Wahl MA. (1991) Pharmacology of curcuma longa. Planta Med. 57: 1-7.

2. Stoner GD, Mukhtar H. Polyphenols as cancer chemopreventive agents. (1995) J. Cell. Biochem. Suppl. 22: 169-180.

3. Huang MT, Lou YR, Ma W, Newmark HL, Reuhl KR, Conney AR. (1994) Inhibitory effects of dietary curcumin on forestomach, duodenal, and colon carcinogenesis in mice. Cancer Res. 54: 58415847.
4. Rao CV, Rivenson A, Simi B, Reddy BS. (1995) Chemprovention of colon carcinogenesis by dietary curcumin, a naturally occurring plant phenolic compound. Cancer Res. 55: 259-266.

5. Conney AH, Lysz T, Ferraro T, Abidi TF, Manchand PS, Laskin JD, Huang MT. (1991) Inhibitory effect of curcumin and some related dietary components on tumor promotion and arachidonic acid metabolism in mouse skin. Adv. Enzyme Regul. 31: 385-396.

6. Huang MT, Ma W, Lu YP, Chang RL, Fisher C, Manchand PS, Newmark HL, Conney AH. (1995) Effects of curcumin, demethoxycurcumin, bisdemethoxycurcumin, and tetrahydrocurcumin on 12-O-tetradecanoylphorbol-13-acetate-induced tumor promotion. Carcinogenesis 16: 2493-2497.

7. Huang MT, Deschner EE, Newmark HL, Wang ZY, Ferraro TA, Conney AH. (1992) Effect of dietary curcumin and ascorbyl palmitate on azoxymethanol-induced colonic epithelial cell proliferation and focal areas of dysplasia. Cancer Lett. 64: 117121.

8. Lu YP, Chang RL, Lou YR, Huang MT, Newmark HL, Reuhl K, Conney AH. (1994) Effect of curcumin on 12-O-tetradecanoylphorbol-13-acetateand ultraviolet B light-induced expression of c-jun and c-fos in JB6 cells and in mouse epidermis. Carcinogenesis 15: 2363-2370.

9. Singh S, Aggarwal BB. (1995) Activation of transcription factor NF-kappa B is suppressed by curcumin. J. Biol. Chem. 270: 24995-25000.

10. Huang TS, Lee SC, Lin JK. (1991) Suppression of c-jun/AP-1 activation by an inhibitor of tumor promotion in mouse fibroblast cells. Proc. Natl. Acad. Sci. U.S.A. 88: 5292-5296.

11. Korutla L, Cheung JY, Mendelsohn J, Kumar R. (1995) Inhibition of ligand-induced activation of epidermal growth factor receptor tyrosine phosphorylation by curcumin. Carcinogenesis 16: 17411745.

12. Rao CV, Simi B, Reddy BS. (1993) Inhibition by dietary curcumin of azoxymethanol-induced ornithine decarboxylase, tyrosine protein kinase, arachidonic acid metabolism and aberrant crypt foci formation in the rat colon. Carcinogenesis 14: 2219-2225.

13. Dietrich WF, Lander ES, Smith JS, Moser AR, Gould KA, Luongo C, Borenstein M, Dove W. (1993) Genetic identification of Mom-1, a major modifier locus affecting Min-induced intestinal neoplasia in the mouse. Cell 75: 631-639.

14. Su LK, Kinzler KW, Vogelstein B, Preisinger AC, Moser AR, Luongo C, Gould KA, Dove WF. (1992) Multiple intestinal neoplasia caused by a mutation in the murine homolog of the APC gene. Science 256: 668-670.

15. MacPhee M, Chepenik KP, Liddell RA, Nelson KK, Siracusa LD, Buchberg AM. (1995) The secretory phospholipase A2 gene is a candidate for the 
Mom 1 locus, a major modifier of ApcMin induced intestinal neoplasia. Cell 81: 957-966.

16. Oshima M, Dinchuk JE, Kargman SL, Oshima H, Hancock B, Kwong E, Trzaskos JM, Evans JF, Taketo MM. (1996) Suppression of intestinal polyposis in Apc delta716 knockout mice by inhibition of cyclooxygenase 2. Cell 87: 803-809.

17. Hinds PW, Finlay CA, Quartin RS, Baker SJ, Fearon ER, Vogelstein B, Levine AJ. (1990) Mutant p53 clones from human colon carcinomas cooperate with ras in transforming primary rat cells: a comparison of the "hot spot" mutant phenotypes. Cell Growth Differ. 1: 571-580.

18. Redston MS, Papadopoulos N, Caldas C, Kinzler KW, Kern SE. (1995) Common occurrence of APC and $\mathrm{K}$-ras gene mutations in the spectrum of colitis-induced neoplasias. Gastroenterology 108: 383392.

19. Folkman J, Haudenschild C, Zetter BR. (1979) Long-term culture of capillary endothelial cells. Proc. Natl. Acad. Sci. U.S.A. 76: 5217-5221.

20. Arbiser JL, Moses MA, Fernandez CA, Ghiso N, Cao Y, Klauber N, Frank D, Brownlee M, Flynn E, Parangi S, Byers HR, Folkman J. (1997) Oncogenic $\mathrm{H}$-ras stimulates tumor angiogenesis by two distinct pathways. Proc. Natl. Acad. Sci. U.S.A. 94: 861-866.

21. Kenyon BM, Voest EE, Flynn E, Folkman J, D'Amato RJ. (1996) A model of angiogenesis in the mouse cornea. Invest. Opthalmol. Vis. Sci. 37: 1625-1632.

22. Boukamp P, Petrussevska RT, Breitkreutz D, Hornung J, Markham A, Fusenig NE. (1988) Normal keratinization in a spontaneously immortalized aneuploid human keratinocyte cell line. J. Cell Biol. 106: 761-767.

23. Hod Y. (1992) A simplified ribonuclease protection assay. Biotechniques 13: 852-853.

24. Prochaska HJ, Santamaria AB, Talalay P. (1992) Rapid detection of inducers of enzymes that protect against carcinogens. Proc. Natl. Acad. Sci. U.S.A. 89: $2394-2398$.

25. Kent KC, Mii S, Harrington EO, Chang JD, Mallette S, Ware JA. (1995) Requirement for protein kinase $\mathrm{C}$ activation in basic fibroblast growth fac- tor-induced human endothelial cell proliferation. Circ. Res. 77: 231-238.

26. Ravindranath V, Chandrasekhara N. (1981) In vitro studies on the intestinal absorption of curcumin in rats. Toxicology 20: 251-257.

27. Wahlstrom B, Blennow G. (1978) A study on the fate of curcumin in the rat. Acta Pharmacol. Toxicol. 43: 86-92.

28. Arbiser JL. (1997) Antiangiogenic therapy and dermatology: a review. Drugs Today 33: 687-696.

29. Kim KJ, Li B, Winer J, Armanini M, Gillett N, Phillips HS, Ferrara N. (1993) Inhibition of vascular endothelial growth factor-induced angiogenesis suppresses tumour growth in vivo. Nature 362: 841-844.

30. O'Reilly MS, Holmgren L, Shing Y, Rosenthal RA, Moses M, Cao Y, Sage EH, Folkman J. (1994) Angiostatin: a novel angiogenesis inhibitor that mediates the suppression of metastases by a Lewis lung carcinoma. Cell 79: 315-328.

31. Gess B, Sandner P, Kurtz A. (1996) Differential effects of kinase inhibitors on erythropoietin and vascular endothelial growth factor gene expression in rat hepatocytes. Pflugers Arch. 432: 426432.

32. Larcher F, Robles AI, Duran H, Murillas R, Quintanilla M, Cano A, Conti CJ, Jorcano JL. (1996) Upregulation of vascular endothelial growth factor/vascular permeability factor in mouse skin carcinogenesis correlates with malignant progression state and activated $\mathrm{H}$-ras expression levels. Cancer Res. 56: 5391-5396.

33. Kohl NE, Omer CA, Conner MW, et al. (1995) Inhibition of farnesyltransferase induces regression of mammary and salivary carcinomas in ras transgenic mice. Nature Med. 1: 792-797.

34. Fahey JW, Zhang Y, Talalay P. (1997) Broccoli sprouts: an exceptionally rich source of inducers of enzymes that protect against chemical carcinogens. Proc. Natl. Acad. Sci. U.S.A. 94: 10367-10372.

35. Fotsis T, Pepper M, Adlercreutz H, Fleischmann G, Hase T, Montesano R, Schweigerer L. (1993) Genistein, a dietary-derived inhibitor of in vitro angiogenesis. Proc. Natl. Acad. Sci. U.S.A. 90: 26902694. 